\title{
Thickness transition of a rigid supramolecular polymer
}

\author{
Laurent Bouteiller, Olivier Colombani, Frédéric Lortie, Pierre Terech
}

Supporting Information

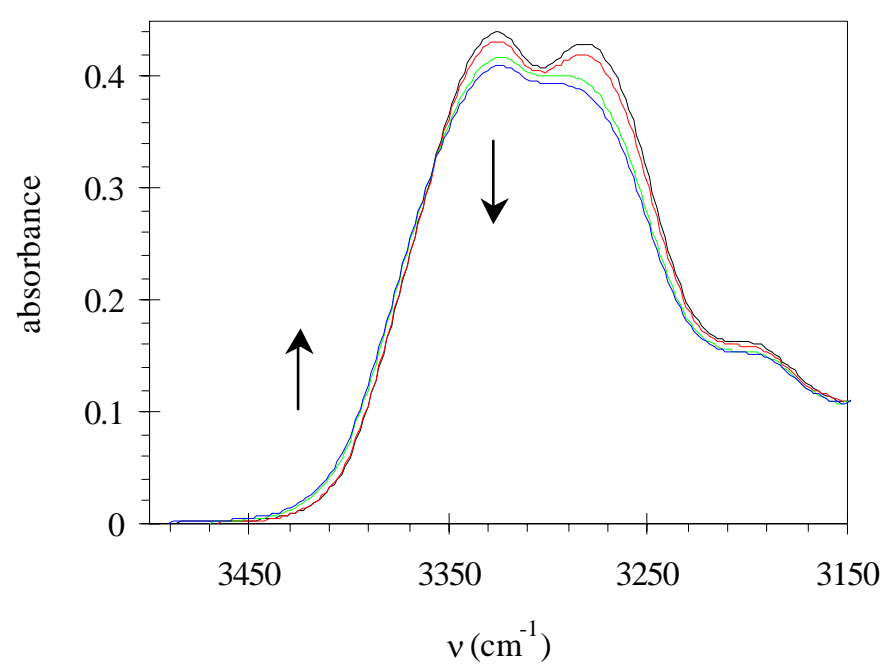

Figure S1. FTIR spectra of a $12.5 \mathrm{mM}$ toluene solution of BuPEH, versus temperature $(22,32$, 36 and $55^{\circ} \mathrm{C}$ ). Arrows indicate the direction of change with increasing temperature. 


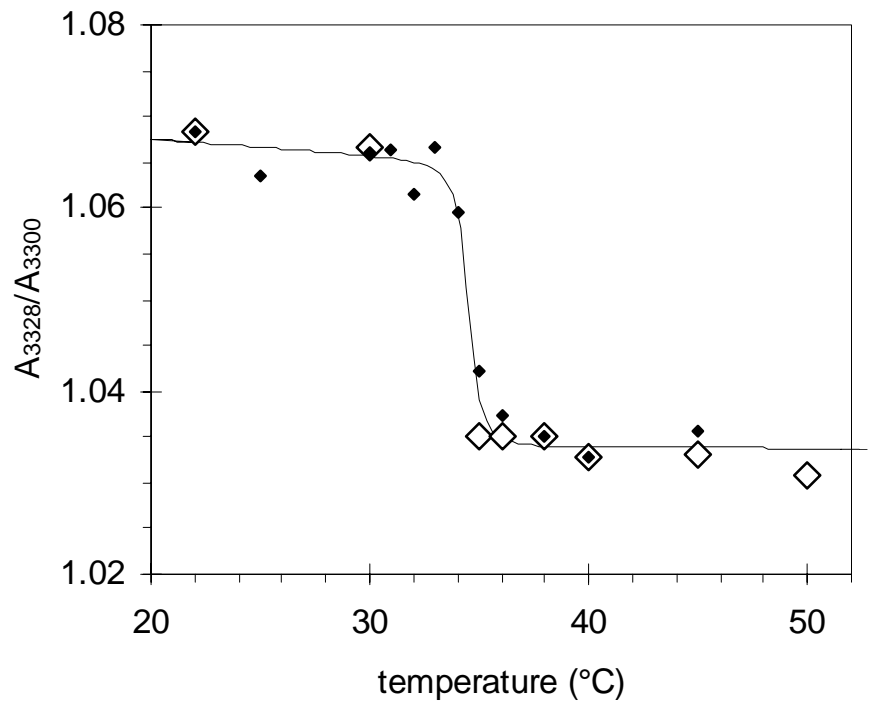

Figure S2. Ratio of absorbances at 3328 and $3300 \mathrm{~cm}^{-1}$ for a $12.5 \mathrm{mM}$ solution of BuPEH in toluene, versus temperature.

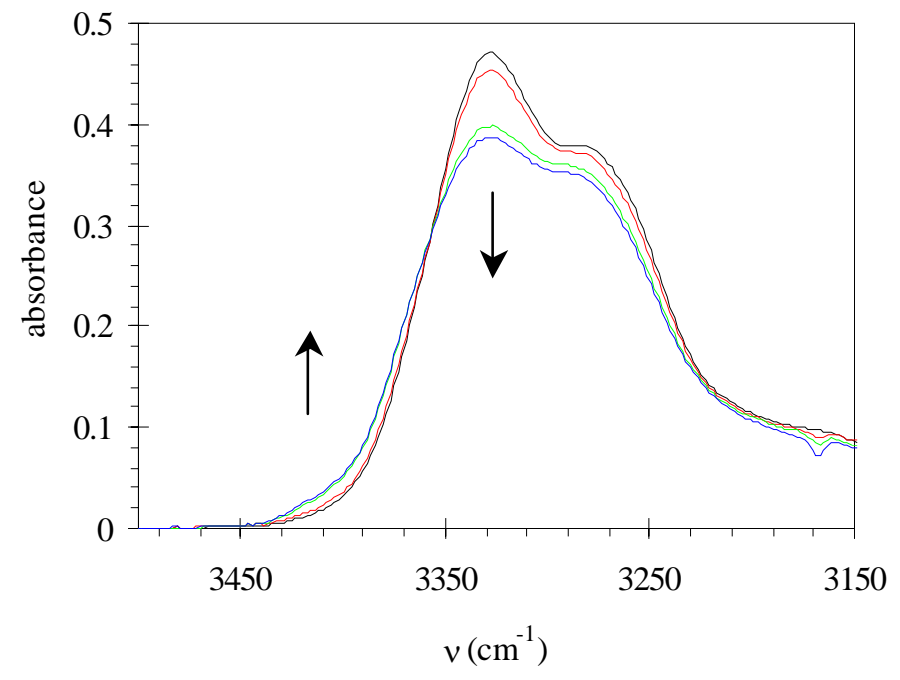

Figure S3. FTIR spectra of a $12.5 \mathrm{mM}$ toluene solution of DMHUT, versus temperature $(50,60$, 65 and $75^{\circ} \mathrm{C}$ ). Arrows indicate the direction of change with increasing temperature. 
Fit of the FTIR data. The model used is taken from P. van der Schoot et al.. ${ }^{1}$ According to this model, the proportion of monomers in the low temperature aggregates is

$$
\alpha=\frac{1}{2}+\frac{s-1}{2 \sqrt{(s-1)^{2}+4 s \sigma}}
$$

where $\sigma$ is a measure of the cooperativity $(0<\sigma \leq 1)$ and $s=\exp \left(f_{s}\right)$, with $f_{s}$ being the additional free energy per bond for a monomer in the low temperature aggregate (the reference being the high temperature aggregate). We use the following approximation ${ }^{1}$

$$
s=\exp \left(\frac{\Delta H_{s}}{k_{B} T} \frac{T-T^{* *}}{T^{* *}}\right)
$$

where $\mathrm{T}$ is the temperature, $\mathrm{T}^{* *}$ is the transition temperature, $\Delta \mathrm{H}_{\mathrm{s}}$ is the variation of enthalpy of association per monomer undergoing the transition, and $\mathrm{k}_{\mathrm{B}}$ is the Boltzman constant.

Then, the normalized absorbance $\mathrm{R}(\mathrm{T})=\mathrm{A}_{\max } / \mathrm{A}_{3300}$ is related to the absorbance of the thick $\left(\mathrm{R}_{\mathrm{L}}\right)$ and thin $\left(\mathrm{R}_{\mathrm{H}}\right)$ filament:

$\mathrm{R}(\mathrm{T})=\alpha \mathrm{R}_{\mathrm{L}}+(1-\alpha) \mathrm{R}_{\mathrm{H}}$

which can be considered to vary linearly with temperature:

$\mathrm{R}_{\mathrm{L}}=\mathrm{p}_{\mathrm{L}}+\mathrm{q}_{\mathrm{L}} \mathrm{T}$ and $\mathrm{R}_{\mathrm{H}}=\mathrm{p}_{\mathrm{H}}+\mathrm{q}_{\mathrm{H}} \mathrm{T}$

Finally, if $\Delta \mathrm{H}_{\mathrm{s}}$ is measured by calorimetry, it is possible to fit the experimental FTIR data with $\mathrm{p}_{\mathrm{L}}, \mathrm{q}_{\mathrm{L}}, \mathrm{p}_{\mathrm{H}}, \mathrm{q}_{\mathrm{H}}, \sigma$ and $\mathrm{T}^{* *}$ as adjustable parameters.

Fit of the SANS data. The following expressions for the form factors were used:

- infinitely long rigid filament of radius of the cross-section $r$, and linear density $\mathrm{n}_{\mathrm{L}}$ :

$$
I=\frac{\pi c}{q} \overline{\Delta b}^{2} \frac{n_{L} M_{0}}{N_{a}}\left[2 \frac{J_{1}(q r)}{q r}\right]^{2}
$$


- short rigid filament of radius of the cross-section r, and length $2 \mathrm{H}$ :

$$
I=\phi \overline{\Delta b}^{2} \pi r^{2} 2 H \int_{0}^{\pi / 2} \frac{\sin ^{2}(q H \cos \alpha)}{(q H \cos \alpha)^{2}} \frac{4 J_{1}^{2}(q r \sin \alpha)}{(q r \sin \alpha)^{2}} \sin \alpha d \alpha
$$

The cross-section is assumed to be circular and the scattering length density profile is assumed to be uniform. $\mathrm{N}_{\mathrm{a}}$ is Avogadro number, $\mathrm{c}$ the concentration $\left(\mathrm{g} \mathrm{cm}^{-3}\right), \phi$ the volume fraction, $\mathrm{M}_{0}$ the molar mass of EHUT and $\mathbf{J}_{1}$ the Bessel function of the first kind. The values of the specific contrast $(\Delta \mathrm{b})$ were calculated based on the measured density of EHUT $\left(1.06 \mathrm{~g} \mathrm{~cm}^{-3}\right)$ and are given in Table $\mathrm{S} 1$.

Table S1: values of the specific contrast used.

\begin{tabular}{lcccccc}
\hline solvant & toluene- $\mathrm{d}_{8}$ & dodecane- $\mathrm{d}_{26}$ & heptane-d $\mathrm{d}_{16}$ & cyclohexane- $\mathrm{d}_{12}$ & $\mathrm{CCl}_{4}$ & $\mathrm{CDCl}_{3}$ \\
\hline$\Delta \mathrm{b}^{2}\left(10^{21} \mathrm{~cm}^{2} \mathrm{~g}^{-2}\right)$ & 2.128 & 3.022 & 2.682 & 3.126 & 0.376 & 0.515
\end{tabular}

Figure S4 shows the attempts to fit the scattering curve of EHUT in toluene at $52^{\circ} \mathrm{C}$. As a first hypothesis, it is assumed that the effect of temperature is to reduce the length of the filaments (or only of a fraction of them), without affecting their thickness. Several situations were tested:

(i) Figure S4a: short filaments of diameter $(2 r=26 \AA)$ and linear density $\left(n_{L}=0.55 \AA^{-1}\right)$. The length of the short filaments was varied.

(ii) Figure S4b: mixture of monomers and long filaments of diameter $(2 r=26 \AA)$ and linear density $\left(n_{L}=0.55 \AA^{-1}\right)$. Scattering from the monomer has been neglected. The monomer fraction was varied.

(iii) Figures S4c to S4f: mixture of short filaments and long filaments of diameter $(2 r=26 \AA)$ and linear density $\left(\mathrm{n}_{\mathrm{L}}=0.55 \AA^{-1}\right)$. The short filament fraction and their length were varied. 

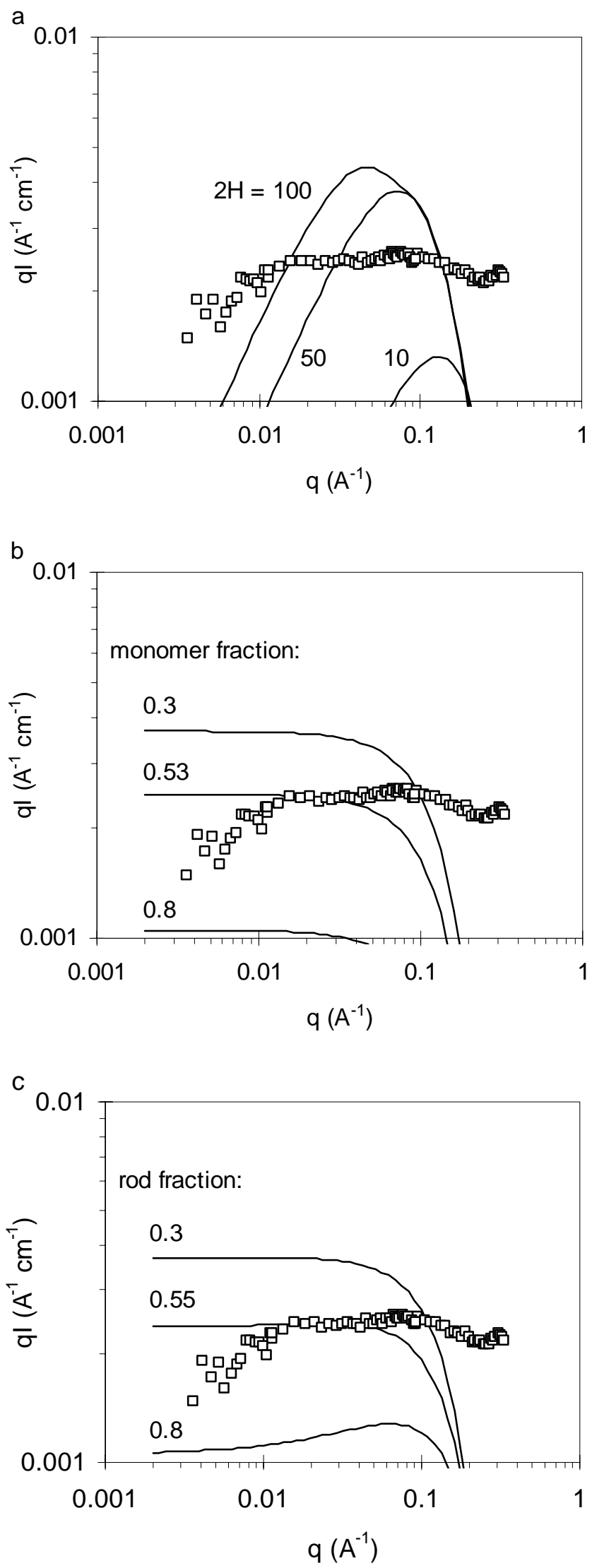

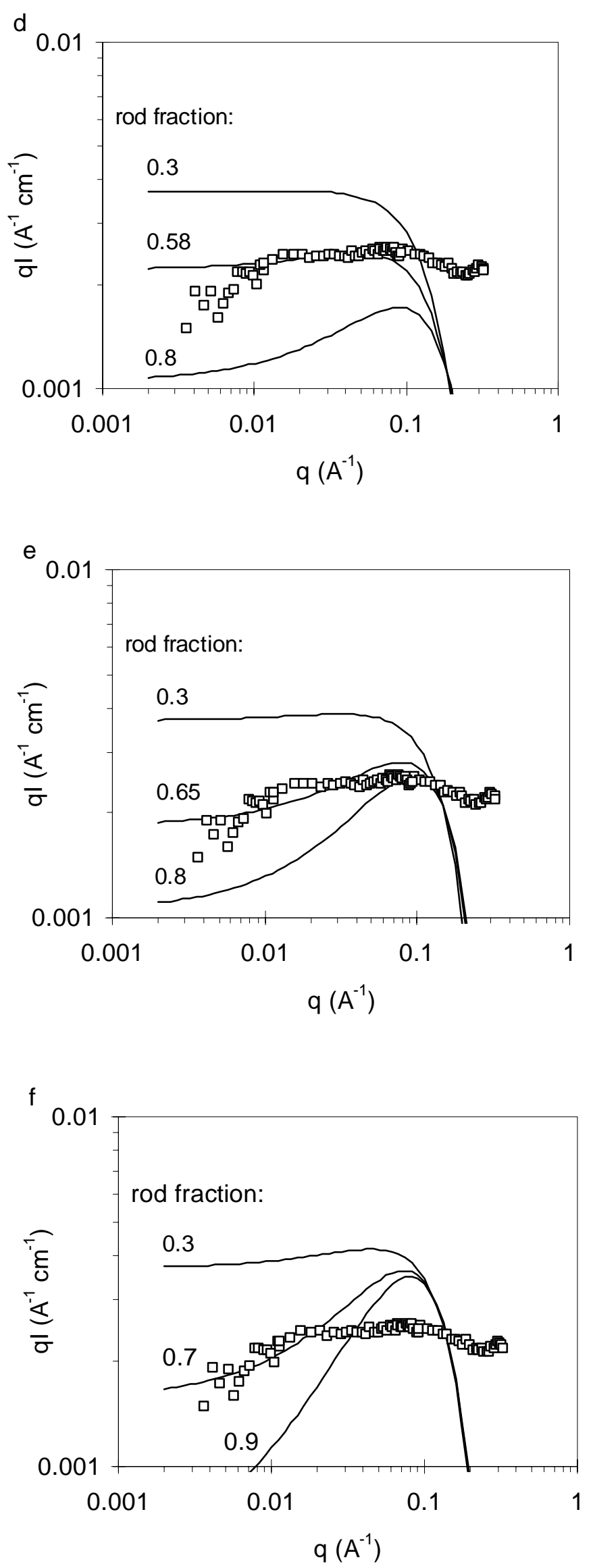
Figure S4. SANS curve for a $4.6 \mathrm{mM}$ solution of EHUT in $\mathrm{d}_{8}$-toluene at $52^{\circ} \mathrm{C}(\square)$, and attempted fits. (a) Short filaments of diameter $(2 \mathrm{r}=26 \AA)$ and linear density $\left(\mathrm{n}_{\mathrm{L}}=0.55 \AA^{-1}\right)$. The length of the short filaments is indicated. (b) Mixture of monomers and long filaments of diameter $(2 \mathrm{r}=26 \AA)$ and linear density $\left(\mathrm{n}_{\mathrm{L}}=0.55 \AA^{-1}\right)$. The monomer fraction is indicated. (c) to (f) Mixture of short filaments and long filaments of diameter $(2 \mathrm{r}=26 \AA)$ and linear density $\left(\mathrm{n}_{\mathrm{L}}=\right.$

$0.55 \AA^{-1}$ ). The short filament fraction is indicated. The length of the short filaments is $2 \mathrm{H}=5 \AA$ (c), $10 \AA$ (d), $20 \AA$ (e), $40 \AA$ (f).

Clearly, none of these attempts correctly reproduces the data, and particularly in the high $\mathrm{q}$ region $\left(q>0.1 \AA^{-1}\right)$. In contrast, as shown in the text of the paper, a fit of good quality is obtained if the diameter of the rigid filaments is allowed to vary (Figure $4 b$ ).

\section{Reference}

(1) van der Schoot, P.; Michels, M. A. J.; Brunsveld, L.; Sijbesma, R. P.; Ramzi, A. Langmuir 2000, 16, 10076-10083. 